\title{
PLANEJAMENTO URBANO-REGIONAL E CRISE AMBIENTAL Região Metropolitana de Curitiba
}

\author{
Cristina de Araújo Lima \\ Professora do Departamento de Arquitetura e Urbanismo da UFPR \\ Francisco Mendonça \\ Professor do Departamento de Geografia e do Programa de Doutorado em Meio Ambiente e Desenvolvimento, \\ Coordenador do Curso de Mestrado em Geografia da UFPR
}

\begin{abstract}
Resumo: As ocupações urbanas em área de mananciais da porção leste da Região Metropolitana de Curitiba, a despeito da existência de um plano de desenvolvimento regional, o Plano de Desenvolvimento Integrado, aprovado em 1978, são o tema central das análises aqui desenvolvidas. As ocupações irregulares da área surgiram nos anos 70 e se efetivaram especialmente na década de 90 , com invasões sobre parcelamentos aprovados desde antes de 1950, quando não havia ainda planejamento regional.

Palavras-chave: planejamento urbano-regional; planejamento ambiental; parcelamento do solo.
\end{abstract}

A cidade e o seu contexto urbano-metropolitano têm se configurado, cada vez mais, num considerável desafio aos estudiosos do urbanismo. Os problemas ambientais urbanos, nesse cenário, demandam a busca de soluções que ultrapassam o campo restrito de disciplinas isoladas, levando o urbanismo a atingir o patamar de campo prático da interdisciplinaridade.

Curitiba, capital do Estado do Paraná, tem se projetado, nacional e internacionalmente nos últimos trinta anos, como uma realidade urbana na qual ter-se-iam equacionados os problemas relativos ao planejamento urbano e à qualidade de vida da população. Mesmo que alguns aspectos do seu contexto possam expressar certo sucesso em políticas e práticas de planejamento urbano, inúmeros são aqueles que, paradoxalmente à positividade imagética da capital paranaense, atestam expressiva degradação socioambiental (Mendonça, 2001). ${ }^{1}$ A cidade constitui-se, sobretudo ante este e outros paradoxos, num verdadeiro laboratório a desafiar os urbanistas para a investigação, afinal, de que maneira configurar-se-ia uma "cidade do Primeiro Mundo" dentro da realidade do "Terceiro Mundo"? Seria mesmo Curitiba uma "Capital Ecológica"? ${ }^{3}$ Que elementos do processo de urbanização estão na gênese dos problemas relativos aos recursos hídricos da Região Metropolitana de Curitiba?

Estas questões possibilitariam o desenvolvimento de vários trabalhos. No presente artigo, todavia, o cerne da análise compreende o terceiro dos três questionamentos anteriores, apontando, de maneira particular, a interação entre o processo de parcelamento do solo urbano na franja leste da Região Metropolitana de Curitiba (RMC) e a problemática dos recursos hídricos da área. ${ }^{4}$

\section{PLANEJAMENTO URBANO E A INSURGÊNCIA DA DIMENSÃO AMBIENTAL}

A cidade atingiu papel determinante no mundo contemporâneo. Segundo Choay (1985), a cultura ocidental, ao aprofundar o conhecimento de si e de suas realizações, percebe a cidade como seu símbolo mais eloqüente. ${ }^{5}$

Em sua formulação inicial, o pré-urbanismo ${ }^{6}$ espelhou uma fase em que o homem se considerava no pleno direito de modificar os recursos naturais e deles usufruir para viabilizar o desenvolvimento da sociedade humana. Entrava em vigor uma ordem nova que buscava adequar as cidades ao modo de produção industrial. ${ }^{7}$ Por volta de 1910 , com a criação do termo "urbanismo", ${ }^{8}$ iniciou-se uma disciplina específica, caracterizada pelo caráter de reflexão e crítica, ancorada em parâmetros científicos e voltada para a função de organizar os elementos urbanos por meio da estruturação administrativa e técnica dos espaços. Esta nova disciplina passa então a ser um campo de especialistas.

Mais tarde, à época do final da Segunda Guerra Mundial, por iniciativa conjunta de profissionais externos ao 
meio dos urbanistas (sociólogos, historiadores, juristas, economistas, psicólogos e outros) e sob a liderança de Patrick Geddes, biólogo escocês, foi proposto um novo método conhecido como "sociological surveys". Sugeriase uma pesquisa ampla do quadro urbano a ser focalizado, anterior à intervenção urbana - desde a demografia, a economia, a história, até as condições sociais e culturais, enfim, todos os aspectos que possibilitassem amplo conhecimento do caso. A pesquisa vasta sobre o conjunto complexo de fatores urbanos deveria ser realizada de forma integrativa por profissionais de diversas formações, fato que deu origem à metodologia do planejamento urbano moderno. Nas palavras de Geddes (apud Choay, 1979:39), "os urbanistas estão acostumados a pensar o urbanismo em termos de régua e compasso, como uma matéria que deve ser elaborada só pelos engenheiros e arquitetos, para os conselhos municipais. Mas o verdadeiro plano (...) é a resultante e a flor de toda a civilização de uma comunidade e de uma época".

Ao analisar as obras urbanas no segundo pós-guerra, construídas na perspectiva do que seria racional, democrático, igualitário e útil para todos, Jacobs (1999) afirmou haver "uma profunda incompreensão do que são as cidades: os processos são a essência". No seu livro, publicado originalmente em 1961, tem-se um dos primeiros brados pelo valor dos processos sociais e das conformações urbanas informais, inusitadas para o rigor científico e o distanciamento do planejamento técnico de então. Para o autor, nesses ambientes urbanos "saudáveis", há uma vitalidade e uma energia de interação social que dependem crucialmente da diversidade, da complexidade e da capacidade de lidar com o inesperado de maneiras controladas, porém criativas. Essa criatividade, que pode gerar soluções além da limitação burocrática dos técnicos, representava uma temeridade para o planejamento urbano modernista, mas, para ele, "é curioso que o planejamento da cidade nem responde à autodiversificação espontânea entre as populações urbanas nem consegue fornecê-la. É curioso que os planejadores das cidades pareçam não reconhecer essa força de autodiversificação nem ser atraídos pelos problemas estéticos de exprimi-la" (Harvey, 1996:74-76). Assim, a liberdade das conformações urbanas encontrou eco apenas algumas décadas depois, no discurso pós-moderno; "a cidade, insiste Raban, é um lugar demasiado complexo para ser disciplinada dessa forma (pelos planejadores)" (Harvey, 1996:17).

Conforme Santos (1994), nas novas conformações da urbanização (Sposito, 1999:86) da contemporaneidade, a cidade incorpora representações diferenciadas, materiais ou não: internamente, na fragmentação do tecido e morfologia urbana e, externamente, pela extrapolação dos limites físicos por meio do fluxo da comunicação mediatizada nos âmbitos nacional e internacional. O espaço urbano globalizado é marcado por relações sociais, econômicas e culturais em constante e acelerada mutação (Santos, 1994). A par desses processos, também a questão relativa ao meio ambiente é evidenciada pela degradação socioambiental generalizada.

No Brasil, a criação das regiões metropolitanas, em 1973, pela Lei Federal Complementar nํ14, constituiu esforço voltado para a coordenação das atividades e problemas urbanos e caracterizou as metrópoles como pólos de desenvolvimento urbano coordenado por entidades específicas. No entanto, desde o início, as entidades coordenadoras do planejamento no âmbito metropolitano ficaram sujeitas às decisões políticas para implementar suas ações e instrumentos de planejamento, como os planos de desenvolvimento regional.

A Região Metropolitana de Curitiba foi objeto de estudo do Iuperj/Minter de 1975 (apud Oliveira, 1995), que avaliou as realizações de planejamento urbano da capital paranaense até a metade dos anos 70 , concluindo que a dimensão técnica dessas soluções não inovava. No "caso de Curitiba", a contribuição para o aprimoramento das técnicas de planejamento urbano nacional não estaria na originalidade, mas sim "em sua dimensão político-institucional. Não é a técnica do planejamento, mas a política do planejamento o fator mais relevante" (Oliveira, 1995:34).

Desde a década de 70, quando o Plano Diretor de Curitiba passou a ser executado e detalhado, observamse rápidas transformações, paralelamente ao aprofundamento da teorização sobre as cidades, momento em que se encontra também o pensamento de Manuel Castells (apud Oliveira, 1995), para quem o "sistema urbano é uma expressão do sistema total do qual ele é parte: o modo de produção capitalista". Para este autor, "o sistema urbano desempenha uma função específica no sistema total, isto é, a reprodução da força de trabalho através da organização do processo de consumo". Para Oliveira (1995), cuja visão vai na mesma perspectiva de Castells, a cidade, através de seus compartimentos espaciais específicos, seus diversos espaços, incrementaria a reprodução da força de trabalho, pois, “(...) na medida em que o consumo se torna uma questão coletiva, a questão urbana se transforma numa questão política". 
Paralelamente à aceleração do consumo do solo metropolitano e à conseqüente degradação ambiental, vem se configurando, há cerca de duzentos anos, o Planejamento Ambiental, em resposta a situações urbanas de crise provenientes do ambiente urbano da Revolução Industrial e tendências já materializadas na cidade barroca, como observa Franco (2000), ao serem derrubados os limites da cidade medieval, propiciando a prevalência dos interesses empresariais, que valorizaram o traçado geométrico e a perspectiva horizontal das grandes avenidas, em detrimento da malha urbana que favorecia a integração social. O Planejamento Ambiental recupera a razão social da cidade, ao se caracterizar pela abordagem conjunta dos elementos do ambiente, pois assume que poucos processos se desenvolvam isoladamente. ${ }^{9}$

Na Região Metropolitana de Curitiba (Mapa 1), o processo de planejamento urbano da capital do Estado tem sido determinante para a ocupação regional. Para muitos, tratase de um modelo a ser seguido. No entanto, na década de 90, a crise ambiental existente no conjunto da metrópole torna-se muito evidente, especialmente quanto ao esgotamento dos mananciais de abastecimento público de água.

\section{ASPECTOS DA OCUPAÇÃO DE ÁREAS DE MANANCIAIS DE ABASTECIMENTO PÚBLICO DE ÁGUA}

Segundo documentação elaborada pelo IPPUC (1997), a cidade de Curitiba, até a década de 60, teve um crescimento caracterizado pelo simples acréscimo de áreas ao redor do centro urbano pioneiro. Após a fase de crescimento acelerado nas duas décadas seguintes, no início dos anos 90, Curitiba apresentou uma taxa anual de crescimento mais baixa $(2,29 \%)$ que a sua região metropolitana (Tabela 1). Também há menor quantidade de bairros com taxas de crescimento superiores à média do município, mas ainda bastante altas em bairros afastados, como São Miguel $(16,89 \%)$, Campo de Santana $(13,43 \%)$ ou Ganchinho $(11,71 \%)$, que até então eram pouco habitados. Ao mesmo tempo, a ocupação nas porções sul e noroeste do município consolida-se, enquanto alguns bairros mais centrais, onde predominam serviços e comércio, perdem população.

A expansão da ocupação urbana, motivada pelo baixo preço dos lotes, foi direcionada para regiões considera-

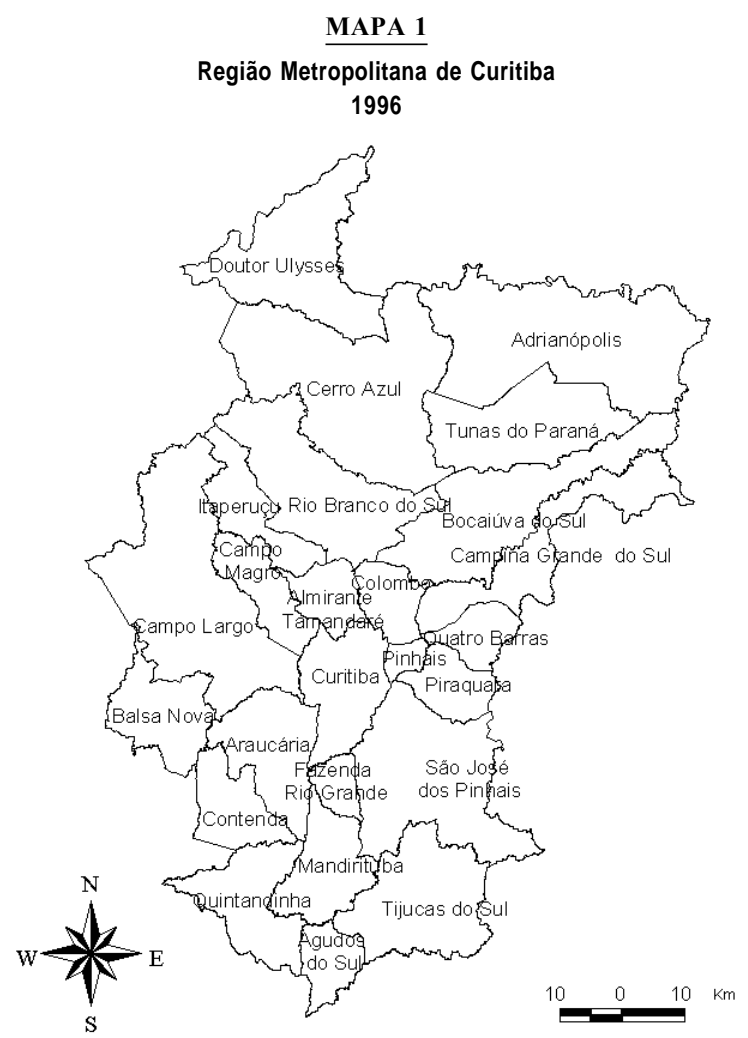

Fonte: Comec - Coordenação da Região Metropolitana de Curitiba/PR. 
das inadequadas para urbanização, que compreendem áreas inundáveis e se distribuem na porção sul do município, em zona fronteiriça a outros municípios. Porém, além da ocupação periférica ainda dentro de Curitiba, esta racionalidade fundamentada no baixo custo da terra e o interesse no usufruto das facilidades urbanas implantadas na capital paranaense levaram à continuidade - algumas vezes apenas parcial - da malha urbana curitibana em loteamentos implantados fora da cidade, porém próximos dos terminais de transporte coletivo urbano da capital. Nesse sentido, o estudo do Ipea e IPPUC (1993) afirma que, "em termos de população bruta e suas taxas de crescimento, o que se confirma para Curitiba, nas duas últimas décadas, é o comportamento da região metropolitana, a periferização da população em busca de áreas a preços mais acessíveis à sua disponibilidade financeira, aliada à acessibilidade no transporte coletivo. Esses bairros estão localizados na área de influência do final dos corredores de transporte estruturais, aí incluindo o eixo da Av. Marechal Floriano Peixoto".

O Plano de Desenvolvimento Integrado da Região Metropolitana de Curitiba - PDI, aprovado em 1978, foi o primeiro plano de organização territorial regional e o primeiro produto da Coordenação da Região Metropolitana de Curitiba - Comec, tendo sido elaborado sobretudo porque a instituição oficial da região metropolitana exigia a elaboração de um plano de desenvolvimento da área. De autoria de uma equipe de planejadores, o PDI (1978) foi pioneiro na articulação de dados regionais, até então nunca analisados sob o recorte metropolitano, e definiu diretrizes funcionais segundo enfoque sistêmico cujo produto deveria ser uma região equilibrada em suas diferentes dinâmicas, na qual o desenvolvimento urbano tivesse o suporte adequado sem que isso prejudicasse as bases produtivas e a qualidade de vida humana.

Fundamentava-se o plano em um modelo de organização territorial, visando a ação metropolitana segundo estratégia intra-regional que previa áreas de contenção, de preservação, de promoção e de dinamização, definidas através da consideração de características e potencialidades do espaço e das atividades existentes. Quanto às áreas dos mananciais de abastecimento público mais importantes para a região, o documento indica que "os centros urbanos nos municípios de Piraquara e São José dos Pinhais deverão ter seus crescimentos controlados de forma mais rígida em virtude de sua localização específica, muito próximos a áreas de captação de água e área inundáveis" (Comec, 1999a:22) e determinava para este vetor leste,
TABELA 1

Evolução Populacional Urbana

Região Metropolitana de Curitiba - 1970-1996

\begin{tabular}{|c|c|c|c|c|}
\hline Municípios & 1970 & 1980 & 1991 & 1996 \\
\hline Total & 660.570 & 1.330 .944 & 1.886 .168 & 2.226 .560 \\
\hline Adrianópolis & 831 & 1.051 & 1.589 & 1.691 \\
\hline Almirante Tamandaré & 4.288 & 27.063 & 59.080 & 80.058 \\
\hline Araucária & 5.473 & 27.128 & 54.262 & 68.648 \\
\hline Balsa Nova & 1.234 & 1.262 & 2.430 & 2.829 \\
\hline Bocaiúva do Sul & 908 & 1.679 & 2.373 & 3.061 \\
\hline Campina Grande do Sul & 319 & 3.783 & 12.722 & 22.984 \\
\hline Campo Largo & 15.927 & 37.401 & 53.892 & 22.984 \\
\hline Cerro Azul & 1.325 & 1.880 & 3.208 & 4.089 \\
\hline Colombo & 1.092 & 54.979 & 110.273 & 145.988 \\
\hline Contenda & 1.122 & 3.498 & 4.823 & 5.469 \\
\hline Curitiba & 584.481 & 1.024 .975 & 1.315 .035 & 1.476 .253 \\
\hline Doutor Ulisses & 314 & 326 & 391 & 523 \\
\hline Fazenda Rio Grande & 617 & 3.265 & 21.855 & 40.499 \\
\hline Itaperuçu & 1.281 & 3.644 & 5.998 & 9.008 \\
\hline Mandirituba & 747 & 3.951 & 4.382 & 5.324 \\
\hline Pinhais & 7.972 & 35.406 & 72.079 & 82.787 \\
\hline Piraquara & 4.141 & 25.521 & 19.359 & 28.109 \\
\hline Quatro Barras & 1.105 & 3.493 & 8.132 & 12.272 \\
\hline Quitandinha & 1.242 & 1.587 & 2.476 & 2.932 \\
\hline Rio Branco do Sul & 3.787 & 10.766 & 17.716 & 15.401 \\
\hline São José dos Pinhais & 21.475 & 56.804 & 111.952 & 151.209 \\
\hline Tijucas do Sul & 389 & 825 & 1.272 & 1.703 \\
\hline Tunas do Paraná & 500 & 657 & 869 & 1.057 \\
\hline
\end{tabular}

Fonte: Comec (1999b); IBGE.

ou "subsistema leste", a estratégia de preservação ambiental, no sentido de conservação.

No chamado subsistema leste, de acordo com as características físico-geográficas e a ocupação existente e prevista, em decorrência de loteamentos aprovados nas décadas anteriores a 50, o PDI/78 considerava que "o posicionamento geográfico de Curitiba, nas cabeceiras do Rio Iguaçu, bem como dos maiores assentamentos urbanos da região, impede que o desenvolvimento urbano seja orientado na direção leste, área de terrenos planos, sob a pena de esgotar importantes reservas de abastecimento de água. Ao sul o crescimento é limitado pelo Rio Iguaçu e suas áreas de inundações. Ao norte, por uma topografia bastante ondulada. Portanto, o desenvolvimento urbano da região é orientado para oeste; embora estas áreas abriguem terrenos medianamente ondulados, oferecem possibilidades de, desviando os obstáculos, condicionar o crescimento de maneira orgânica.

Atualmente a Comec procede à reavaliação do PDI, pois, desde as leituras mais recentes, percebeu-se que as estratégias previstas no plano não haviam se tornado reais. Durante os anos 90, houve identificação mais clara da 
Planejamento Urbano-Regional e Crise Ambiental: Região Metropolitana...

concentração espacial dos problemas regionais localizados nas áreas periféricas. Curitiba contou ao longo dos anos com um processo de planejamento exemplar, que de certa forma repercutiu numa intensiva urbanização das áreas periféricas, onde a legislação era mais fragmentada e permissiva, cenário só alterado com o advento da Lei Federal no 6.799/79, que regulou o parcelamento do solo em áreas urbanas. ${ }^{10} \mathrm{~A}$ nova percepção do espaço metropolitano, com a presença marcante do desenvolvimento urbano da cidade-pólo e do seu entorno imediato - a Grande Curitiba - mostrou a forte vinculação entre o centro urbano mais antigo e as recentes áreas periféricas em processo de urbanização.

\section{Loteamentos Aprovados}

Segundo dados da Comec, desde períodos anteriores a 1950 , estendendo-se até 1994 , foram aprovados regularmente 229.618 lotes na RMC.

Nos anos 50, verificou-se o efetivo início do processo de parcelamento do solo regional, e de forma bastante expressiva, atingindo cerca de $33 \%$ do total de lotes aprovados na RMC até 1994. Agrupando-se os dados disponíveis em etapas, observa-se que até 1949, com exceção da capital, apenas três municípios da região metropolitana - Araucária, Colombo e São José dos Pinhais - apresentavam parcelamentos do solo de características urbanas (Tabela 2).

Naquele momento não havia base para argumentação contra a ocupação urbana devido ao desconhecimento exato da dimensão e da fragilidade do aqüífero cárstico em Colombo e municípios vizinhos, ou da escala que atingiriam os efeitos degradadores da evolução do adensamento populacional regional de forma legal ou ilegal nas áreas de mananciais da porção leste. Cabe, no entanto, a constatação da origem de um processo de degradação ambiental iniciado há cerca de 50 anos e que foi deflagrado, em sua maioria absoluta, justamente em áreas de fragilidade em relação a grandes densidades humanas, no caso para manutenção do recurso natural de água, enquanto fator fundamental para a ocupação da região. Portanto, o foco da maioria absoluta das primeiras manifestações do processo contemporâneo de parcelamento do solo regional foram as áreas metropolitanas de mananciais de abastecimento público no leste.

O pequeno número de lotes aprovados nos municípios de Araucária, Colombo e São José dos Pinhais expressa a fraca dinâmica do parcelamento urbano então existente no período anterior a 1950. Na década seguinte, no entanto,
TABELA 2

Total de Lotes Aprovados

Região Metropolitana de Curitiba - 1949-1994

\begin{tabular}{|c|c|c|c|c|c|c|}
\hline \multirow{2}{*}{ Municípios } & \multicolumn{2}{|c|}{ Até 1949} & \multicolumn{2}{|c|}{$1950-59$} & \multicolumn{2}{|c|}{ Total até 1994} \\
\hline & $\begin{array}{c}\text { №s } \\
\text { Absolutos }\end{array}$ & $\%$ & $\begin{array}{c}\text { №s } \\
\text { Absolutos }\end{array}$ & $\%$ & $\begin{array}{c}\text { №s } \\
\text { Absolutos }\end{array}$ & $\%$ \\
\hline Total & 676 & 0,29 & 75.729 & 32,98 & 229.618 & 100,00 \\
\hline Almirante Tamandaré & - & - & 3.192 & 14,96 & 21.342 & 100,00 \\
\hline Araucária & 123 & 0,67 & 1.525 & 8,29 & 18.386 & 100,00 \\
\hline Balsa Nova & - & - & - & - & 533 & 100,00 \\
\hline Bocaiúva do Sul & - & - & 247 & 18,88 & 1.308 & 100,00 \\
\hline Campina Grande do Sul & - & - & 3.080 & 41,48 & 7.425 & 100,00 \\
\hline Campo Largo & - & - & 4.780 & 30,19 & 15.831 & 100,00 \\
\hline Colombo & 311 & 0,90 & 9.746 & 28,12 & 34.658 & 100,00 \\
\hline Contenda & - & - & - & - & 637 & 100,00 \\
\hline Fazenda Rio Grande & - & - & 1.297 & 14,86 & 8.730 & 100,00 \\
\hline Itaperuçu & - & - & - & - & 3.680 & 100,00 \\
\hline Mandirituba & - & - & 94 & 12,16 & 773 & 100,00 \\
\hline Pinhais & - & - & 10.954 & 41,94 & 26.116 & 100,00 \\
\hline Piraquara & - & - & 21.427 & 61,56 & 34.806 & 100,00 \\
\hline Quatro Barras & - & - & 1.298 & 22,38 & 5.801 & 100,00 \\
\hline Rio Branco do Sul & - & - & 83 & 2,02 & 4.113 & 100,00 \\
\hline São José dos Pinhais & 242 & 0,53 & 18.006 & 39,59 & 45.479 & 100,00 \\
\hline
\end{tabular}

Fonte: Comec (1999b).

foram quebrados todos os recordes registrados até 1994, no que se refere a números de lotes aprovados pelos municípios que comporão oficialmente, em 1973, a região metropolitana em estudo. Com um total de 75.729 lotes aprovados em 13 municípios, tem-se, nos anos 50, uma média por município de 5.825 lotes aprovados em dez anos, o que significa um crescimento de $2.589 \%$ em comparação com o período anterior.

Os anos 50 confirmam a constatação anterior em relação à ocupação regional deflagrada na área de mananciais leste. Através dos dados para este período, verifica-se que o grande destaque de parcelamentos urbanos desta década ocorreu no município de Piraquara, que aprovou, neste intervalo de dez anos, cerca de $60 \%$ do total de lotes aprovados pelo município até 1994, ou seja, mais de 40 anos depois. A quantidade de lotes aprovados em Piraquara foi ainda maior do que no município vizinho de São José dos Pinhais, líder do processo no leste metropolitano até então.

Desde as origens do tipo de parcelamento aqui focalizadas na RMC, os municípios do leste metropolitano que contêm em seus territórios os mananciais mais importantes para abastecimento regional - Pinhais, Piraquara e São José dos Pinhais - tiveram um desempenho determinante para tornar significativo este processo. No entanto, ao mesmo tempo, incorporaram a seus territórios elementos potenciais para uma ocupação incompatível com valores 
ambientais. A aprovação de loteamentos dispersos, desconectados da malha urbana estabelecida, era prática realizada sem parâmetros para avaliação dos danos sociais, econômicos e ambientais futuros.

Sem dúvida o município de maior número de lotes aprovados é o de Piraquara, integrante da área de mananciais regionais do leste. Até 1949 não havia registro de loteamentos em Piraquara, mas, nos dez anos seguintes, ocorreu a aprovação recorde de 21.427 lotes, valor que, na década de 60 , caiu para menos de $1 / 5$ do total efetivado nos anos 50 .

Outro destaque surpreendente pelo alto número de lotes aprovados consiste no caso do então Distrito de Pinhais, pertencente ao município de Piraquara, do qual emancipou-se em 1992. O distrito industrial congregava uma série de indústrias chamadas "de fundo de quintal". Localizada exatamente na divisa com Curitiba, esta localidade apresenta problemas de suscetibilidade a inundações, baixa declividade dificultando a drenagem natural e escoamento superficial. Na década de 50, contudo, verificou-se a aprovação de nada menos do que 10.954 lotes nesta porção regional, que está também em área de mananciais importantes. Em um patamar bem abaixo, apesar de não menos importantes, ficam os municípios de Campo Largo (4.780 lotes), Almirante Tamandaré (3.192 lotes) e Campina Grande do Sul (3.080 lotes).

Esta posição significativa do parcelamento na área de mananciais leste em relação ao total de lotes aprovados na RMC, entre 1950 e 1959, pode ser visualizada no Gráfico 1.

Portanto, houve uma explosão na quantidade de lotes aprovados em vários municípios metropolitanos na década de 50, sendo que os maiores números envolvem áreas dos mananciais do leste regional $(66,52 \%)$.

\section{GRÁFICO 1}

Comparativo do Total de Lotes Aprovados na Década de 50 Região Metropolitana de Curitiba e

Municípios dos Mananciais do Leste Metropolitano - 1950-59

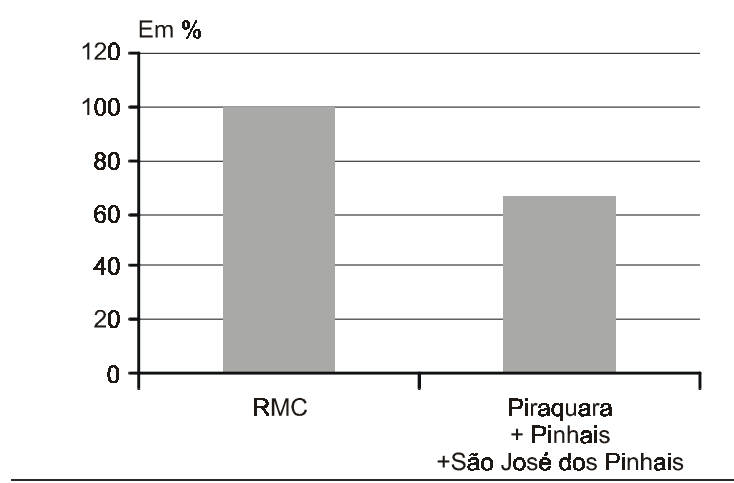

Fonte: Comec (1999b).
Na década de 60, na Região Metropolitana de Curitiba, aprovou-se metade do total de lotes da década anterior. Em relação à proteção dos mananciais, o governo estadual da época procedeu à desapropriação de loteamentos aprovados em margens de rios, o que desestimulou a ocupação.

$\mathrm{Na}$ década 70, sobressai o caráter definitivo de aceleração da ocupação periférica regional, através dos destaques absolutos de número de lotes aprovados nos municípios de Almirante Tamandaré e Colombo, em locais ambientalmente inadequados e desprovidos de estruturação urbana. Tal situação assumiu papel determinante no quadro dos problemas regionais 20 anos depois.

A partir da interrupção da trajetória acelerada de parcelamento do solo metropolitano ocorrida na década anterior, os anos 80 configuram-se como uma retomada de crescimento da ocupação do solo em condições de maior estabilidade quanto ao parcelamento do solo regional. Os grandes picos de parcelamento atingem valores menores que os da década de 70 .

Ao mesmo tempo, verificam-se uma queda na intensidade do processo em geral e uma retomada de crescimento, porém de forma mais expandida, abrangendo maior número de municípios metropolitanos. Neste momento, observam-se duas faces desconexas na configuração espacial da Região Metropolitana de Curitiba: enquanto a realidade evidencia com maior vigor uma discrepância com as estratégias do plano regional - PDI de 1978, é aprovada a maioria das legislações de uso e ocupação do solo nos municípios, conforme as estratégias do mesmo PDI.

A Região Metropolitana de Curitiba reúne atualmente cerca de $27 \%$ da população do Estado - uma proporção menor que a média das regiões metropolitanas do país (38,61\%) (IBGE, 1991 e 1996) -, mas demonstra crescimento de $266,27 \%$ em relação ao período inicial da aceleração do processo de urbanização regional, nos anos 50 .

No Gráfico 2 apresenta-se um resumo das análises precedentes, referente ao número de lotes aprovados na RMC, por município e por década, em seus valores médios e máximos, visando delinear a seqüência do fenômeno da ocupação do solo urbano metropolitano.

Comparando-se os dados relativos ao número de lotes aprovados com o crescimento populacional no período 1949-94, observa-se que o montante de lotes aprovados nos seis períodos torna-se insignificante. No entanto, cabe a observação referente à taxa de ocupação de cada lote e coeficiente de aproveitamento, que no caso em foco normalmente restringe-se a uma família composta por 3,67 pessoas, pela média regional (Comec, 1999b) ou, às vezes, mais de uma 


\section{GRAFICO 2}

Evolução do Número de Lotes Aprovados, Considerando os Valores Médios e Máximos Região Metropolitana de Curitiba (1) - 1949-94

Número Médio número Máximo

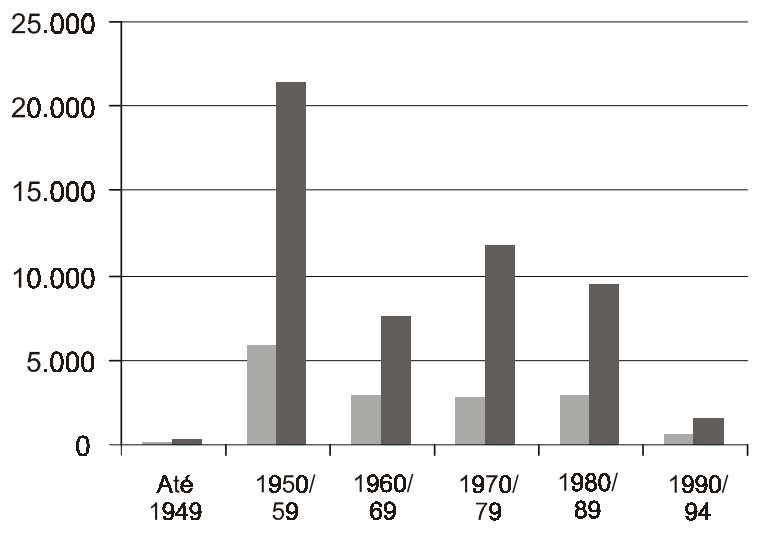

Fonte: Comec (1999b).

(1) Exceto o município de Curitiba.

família. Sem agrupar o número de habitantes por família em cada lote, verifica-se o grande aumento populacional a partir dos anos 70. Considerando-se a diferença de ângulo do gráfico de crescimento populacional na RMC nos períodos analisados, conclui-se que, caso o número de lotes aprovados permanecesse no ritmo apresentado entre 1960 e 1970, chegar-se-ia ao final dos seis períodos com cerca de 340.000 lotes aprovados na RMC. No entanto, considerando a taxa de crescimento entre 1979 e 1994, chegar-se-ia ao final dos períodos com mais de 800.000 lotes aprovados na RMC. Cabe observar que este último número calculado refere-se à tendência real, em andamento.

Visualizam-se algumas evidências advindas da comparação entre o ritmo do crescimento populacional e o número de parcelamentos de solo urbano na região, principalmente em relação à defasagem entre os dois fatores, lembrando-se que os dados apresentados não incluem Curitiba, município que abriga mercado imobiliário de maior porte e dinamismo, mas que envolve valores incompatíveis com o poder aquisitivo da população que adquire os lotes na periferia.

Voltando a atenção para a ocupação em área de mananciais, verifica-se que os municípios de Pinhais, Piraquara e São José dos Pinhais têm sido objeto de intenso processo de parcelamento do solo, em áreas urbanizadas ou não, dentro do perímetro urbano ou em zonas rurais. Inicialmente conformou-se um quadro de ocupação em potencial que, no entanto, assumiu escala e significado crescentemente mais significativos no decorrer dos últimos 50 anos.

Pelos dados anteriormente apresentados, verifica-se que esses parcelamentos, regularmente aprovados, atingiram um pico não mais repetido na década de 50 , estendendo uma grade preliminar de 75.729 lotes distribuídos em treze municípios, sendo que Piraquara liderou esta etapa, aprovando mais de 21.000 lotes. Cabe destacar o fato de que grande parte destes parcelamentos - implantados ou não - encontram-se em espaços de grande proximidade com o pólo metropolitano, sendo exemplo o território desmembrado de Piraquara, em 1992, que veio a se constituir no município de Pinhais.

No geral, observa-se uma dinâmica regional de ocupação bastante intensa e que vem se acelerando, com uma taxa de crescimento populacional regional em torno de 3,43\% a.a., enquanto a população do Estado está crescendo $1,24 \%$ (IBGE, 1991 e 1996). Este ritmo acelerado de crescimento, que se destaca entre as demais regiões metropolitanas do país, traz alguma inquietação a respeito da qualidade de vida dos habitantes, especialmente em relação aos recursos fundamentais para a sobrevivência. Dentre estes está a água, cuja principal fonte natural encontra-se nos mananciais de abastecimento público.

Conforme estudos de especialistas, os recursos hídricos da RMC são limitados e seu esgotamento está próximo, num horizonte de 35 anos. Por outro lado, a necessidade de habitação segue aumentando, ao longo das décadas, no compasso do crescimento populacional, tanto vegetativo quanto de migrações, estas últimas fruto principal da disseminação de uma imagem de cidade sem problemas, com excelente qualidade de vida e com forte poder de atratividade. A questão da contaminação dos mananciais de abastecimento público de água está estreitamente vinculada à realidade econômica e social e depende da capacidade de atendimento às demandas públicas e da mobilização do Estado, ou seja, a efetividade de políticas públicas.

No âmbito das ações do Estado, encontram-se aquelas referentes ao planejamento urbano e regional, que objetivam a organização espacial das atividades da sociedade no território. A questão do parcelamento do solo metropolitano extrapola a apropriação da base física para delinear os contornos da vida urbana em seus quesitos relativos à qualidade. Além dos dados demográficos, aqueles referentes à renda são importantes para o delineamento da população que ocupará, no caso, os lotes aprova- 
dos. Os futuros moradores farão parte da massa de contribuintes que, com o pagamento de taxas, tarifas e outras modalidades de imposto, mantêm boa parte dos serviços públicos urbanos, viabilizando a manutenção e a renovação dos atendimentos gerais da cidade.

Na RMC, segundo dados do IBGE provenientes do Censo Populacional de 1991, 40,12\% dos chefes de família recebem até dois salários mínimos por mês e 33, 11\% ganham até cinco salários mínimos mensais. Ou seja, na parcela com teto salarial de dois salários, provavelmente as necessidades básicas consumirão a renda. Mesmo entre aqueles cujos rendimentos não ultrapassam os cinco salários, considerando uma família de três a quatro pessoas, ${ }^{11} \mathrm{O}$ padrão de vida será um tanto restrito para formação profissional de nível médio a alto, acesso a conhecimento atualizado, novas tecnologias e inúmeros exemplos de atividades de crescimento do potencial humano. Como conseqüência, caberá ao próprio Estado suprir espaços públicos com recursos materiais e humanos para o desenvolvimento dos seus cidadãos. Porém, antes das condições complementares para a qualidade de vida, existem, na área em estudo, questões fundamentais a serem resolvidas.

A questão habitacional configura-se num dos maiores desafios para o poder público. Antes mesmo de melhoria dos padrões habitacionais existentes, visando otimização do consumo de energia, ou utilização de materiais e processos que causem menos impacto ao ambiente, devem-se verificar as condições de pobreza extrema, em que os cidadãos utilizam-se de subabitações, configurando um problema social e de responsabilidade do Estado. Nesse aspecto, é interessante verificar a escala assumida pelo problema das ocupações irregulares da região, em especial nos municípios aqui enfocados pela sua condição de proximidade com os mananciais de abastecimento público de água.

Um dos pontos que não têm sido considerados devidamente no planejamento e na gestão regionais diz respeito à interligação das sub-bacias hidrográficas, especialmente a disseminação da poluição gerada a montante que atinge as áreas a jusante. Considerando-se que as duas captações da Sanepar na bacia do Alto Iguaçu localizam-se uma no Rio Iraí, entre os municípios de Piraquara e Pinhais, e a outra no Rio Iguaçu, no município de São José dos Pinhais, divisa com Curitiba, verifica-se que a contaminação das sub-bacias decorrentes de ocupações, regulares e irregulares, observadas na área de estudo, apresenta-se previamente carregada à altura de Pinhais com o volume do Rio Palmital, cujas nascentes estão no município de Colombo, ao norte.
A várzea do Rio Palmital vem sendo progressivamente ocupada de forma irregular desde os anos 70, transformando-se num grande foco de contaminação dos mananciais usados no abastecimento regional público de água. Essa contaminação é causada, dentre outros motivos, pela ocupação conhecida por "Zumbi dos Palmares", localizada no município de Colombo, que é uma das três maiores ocupações regionais apresentando mais de 1.000 unidades de subabitações em 1997, segundo Comec, ou seja, uma população de cerca de 3.800 habitantes ${ }^{12}$ assentados, sem infra-estrutura, sobre o leito de inundação do rio. O Rio Palmital encontra o Rio Iraí na divisa entre os municípios de Pinhais e Piraquara, unindo-se mais à frente, na divisa com Curitiba, ao Rio Atuba, no chamado "Marco Zero do Iguaçu”. Na bacia do "Altíssimo Iguaçu”, encontram-se as duas captações de água do lado leste da RMC, que representam $69,23 \%$ da produção de água do principal sistema de abastecimento público regional, denominado "Sistema Integrado Curitiba", junto à BR-277. Este sistema abastece Curitiba, Araucária, Colombo (em cerca de 50\%), Pinhais e São José dos Pinhais.

Tal qual vasos comunicantes, os rios de uma mesma bacia desenvolvem sua dinâmica natural independente dos limites político-administrativos municipais ou de outra natureza abstrata, impostos pelo homem. Quando analisam-se dados, os números passam a ser sobretudo indicadores de uma realidade concreta que perfaz todo um quadro de qualidade de vida. Entre 1992 e 1997, o número de ocupações irregulares nos municípios do leste enfocados no trabalho - Pinhais, Piraquara e São José dos Pinhais cresceu cerca de 4,5 vezes em cinco anos, o que pode significar que, a cada ano, instalaram-se precariamente nestes municípios cerca de 5.783 pessoas ou, a cada dia, mais de 15 pessoas, ou quatro famílias, considerando uma média regional de componentes da unidade familiar. ${ }^{13}$ Este valor atinge, em 1997, um total de 38.221 pessoas, nos três municípios, em estado de carência generalizada, pois as ocupações irregulares normalmente formam um quadro de extrema precariedade, não apenas quanto aos assentamentos em si, na sua materialidade, mas principalmente no que se refere à precariedade física, de formação profissional e da cidadania dos seus moradores.

A respeito da evolução das ocupações irregulares na região metropolitana, cabe destacar que o número destas unidades existentes nos três municípios analisados é 2,9 vezes maior que o valor apresentado pela RMC no mesmo período. ${ }^{14}$

A variação das taxas de crescimento das ocupações irregulares ocorridas nos municípios da região metropoli- 
tana, entre 1992 e 1997, configurou focos para tal tipo de assentamento. $\mathrm{Na}$ liderança encontra-se o município de Piraquara, com uma taxa de 69,81\%, seguido por São José dos Pinhais e Bocaiúva do Sul. Estes três municípios são integrantes do vetor leste de crescimento metropolitano.

Neste momento é necessário salientar a gravidade das ocupações localizadas em áreas de mananciais. Ao leste, sobre mananciais superficiais, e na direção norte, sobre mananciais subterrâneos cársticos. Além disso, cabe também destacar o grande número de ocupações efetivadas no município de São José dos Pinhais, o segundo maior número da região metropolitana, com taxa de crescimento em 34,93\%, entre 1992 e 1997.

Portanto, pode-se concluir que as ocupações irregulares de maior amplitude quanto à ocupação espacial situam-se em áreas metropolitanas menos adequadas para recebê-las, no caso, em razão da sua localização em áreas de mananciais de abastecimento público de água, tanto ao norte como a leste da região. O grande destaque fica com os municípios de Piraquara e São José dos Pinhais, que apresentam números muito altos, especialmente o primeiro. Esta constatação demonstra o risco ambiental advindo do processo de ocupação que atinge importantes áreas de mananciais de abastecimento público de água, como nos municípios citados.

O Planejamento Urbano Ambiental coloca-se como perspectiva a ser implementada, pois, de forma similar ao que houve com o PDI, os seus instrumentos, estruturais e não-estruturais, devem ser executados. Tendo em vista as condições atuais da RMC, especialmente em relação à pobreza da população periférica, é necessário considerar um enfoque ambiental em relação ao planejamento urbano-regional. Isto exige adotar princípios amplos, de cunho socioambiental, como os privilegiados pela "Agenda 21 ", que aborda as dimensões sociais e econômicas, a conservação e o gerenciamento dos recursos para desenvolvimento o fortalecimento do papel dos grupos principais, como a infância e a mulher. A Agenda 21, para o urbano, é um guia para a articulação de políticas locais, como as referentes ao espaço urbano.

\section{NOTAS}

E-mail dos autores: chris@cce.ufpr.bre chico@cce.ufpr.br

1. Mendonça (2001) apresenta uma análise embasada em dados e que explicita o paradoxo entre o citymarketing e os graves problemas relativos à degradação ambiental em Curitiba e sua região metropolitana.

2. Slogan veiculado na década de 80 pela administração pública municipal de Curitiba para enfatizar aspectos da qualidade de vida da cidade.

3. Slogan criado pelo Instituto de Pesquisa e Planejamento Urbano de Curitiba (IPPUC), no início da década de 90 , com base no índice de áreas verdes da cidade (cerca de $50 \mathrm{~m}^{2} /$ hab conforme dados da própria prefeitura) e sua associação com o modelo de transporte coletivo implantado, tomado como sucesso pela administração municipal.

4. Esta problemática foi o tema central da tese de doutorado de um dos autores do presente texto (Lima, 2000).

5. Analisando os escritos de diversos autores a respeito do espaço e da cidade, Choay (1985:68) ressalta a condição privilegiada que o comentário sobre a cidade possibilita ao expressar uma visão de mundo e uma idéia da natureza humana.

6. Referência à denominação utilizada por Choay (1979:61-136).

7. São dessa época várias proposições, teóricas e práticas, elaboradas por profissionais de diversas categorias, como historiadores, economistas e políticos. Destacam-se as obras de Owen, Fourier, Cabet e outros, como descreve Benevolo (1983).

8. Como idéia e pensamento, as origens do urbanismo remontam ao início da Renascença, no século XV. Para Harouel, o urbanismo foi definido em 1867 por Cerda, no que concorda Choay (1985). No entanto, quanto à adoção do termo pela realidade atual, considera-se neste trabalho a data apresentada por Bardet apud Choay (1979:2-3).

9. O exemplo da importância da permeabilidade do solo urbano remete a um conjunto de ações de conservacionistas, cujo sucesso depende das ações humanas (Gibbons, 1996:243).

10. Constitui exemplo a desapropriação ocorrida na gestão de Parigot de Souza, no governo estadual, com área de loteamento adquirida pela Sanepar, empresa estatal de distribuição de água e saneamento.

11. Composição familiar média na RMC é de 3,67 pessoas (Comec, 1999b:52). 12. Número médio de moradores no município de Colombo, segundo Comec (1999b). 13. Adotando a média entre os valores dos três municípios $(3,67$ pessoas/domicílio), segundo Comec (1999b).

14. Na RMC o número das ocupações irregulares cresceu $152,22 \%$ durante os cinco anos contemplados, enquanto em Pinhais, Piraquara e São José dos Pinhais o crescimento das unidades foi de $442,58 \%$ no mesmo período (Comec, 1999b).

\section{REFERÊNCIAS BIBLIOGRÁFICAS}

BENEVOlO, L. História da cidade. São Paulo, Perspectiva, 1983. CHOAY, F. O urbanismo. São Paulo, Perspectiva, 1979. . A regra e o modelo. São Paulo, Perspectiva, 1985.

COMEC. Plano de desenvolvimento Integrado da Região Metropolitana de Curitiba-PDI. Curitiba, 1978. . Metrópolis em revista. Curitiba, 1999a.

. Proposta de implantação da área de interesse social GuaritubaPiraquara. Curitiba, 1999b.

FRANCO, M.A.R. Planejamento ambiental para a cidade sustentável. São Paulo, Annablume, 2000.

GIBBONS, C. “Impervious surface coverage.” APA Journal. Chicago, v.62, n.2, 1996. HARVEY, D. Condição pós-moderna. São Paulo, Loyola, 1996.

IBGE. Censo populacional. Rio de Janeiro, 1991. Contagem populacional. Rio de Janeiro, 1996.

IPEA/IPPUC. Monitoração da gestão urbana. Curitiba, 1993.

IPPUC. Planejamento urbano - Curitiba. Curitiba, 1997.

JACOBS, J. Morte e vida das grandes cidades americanas. São Paulo, Martins Fontes, 1999.

LIMA, C.A. Ocupação de área de mananciais na Região Metropolitana de Curitiba: do planejamento à gestão ambiental urbana-metropolitana. Tese de Doutorado. Curitiba, Universidade Federal do Paraná, 2000.

MENDONÇA, F. "O mito da 'capital ecológica': aspectos da problemática ambiental urbana de Curitiba e Região Metropolitana". $8^{\circ}$ Encuentro de Geografos de America Latina. Anais... Santiago, mar. 2001 (CD-ROM).

OLIVEIRA, D. A política do planejamento urbano: o caso de Curitiba. Tese de Doutorado. Campinas, Unicamp, 1995.

SANTOS, M. Técnica, espaço, tempo. São Paulo, Hucitec, 1994

SPOSITO, M.E.B. "A urbanização da sociedade: reflexões para um debate sobre as novas formas espaciais." In: DAMIANI, A.L.; CARLOS, A.F.A. e SEABRA, O.C. de L. (orgs.) O espaço no fim de século: a nova raridade. São Paulo, Contexto, 1999. 